\title{
Enhancing the thermomechanical behaviour of poly(phenylene sulphide) based composites via incorporation of covalently grafted carbon nanotubes
}

\author{
Ana M. Díez-Pascual ${ }^{\mathrm{a}, *}$, Mohammed Naffakh ${ }^{\mathrm{b}}$ \\ anstituto de Ciencia y Tecnología de Polímeros (ICTP-CSIC), Juan de la Cierva 3, 28006 Madrid, Spain \\ ${ }^{b}$ Universidad Politécnica de Madrid, Departamento de Ingeniería y Ciencia de los Materiales, Escuela Técnica Superior de Ingenieros Industriales, José Gutiérrez Abascal 2 , \\ 28006 Madrid, Spain
}

Keywords:

A. Thermoplastic resin

Carbon nanotubes

B. Thermomechanical

E. Extrusion

\begin{abstract}
A B S T R A C T
The thermal and thermomechanical properties of poly(phenylene sulphide) (PPS) based nanocomposites incorporating a polymer derivative covalently anchored onto single-walled carbon nanotubes (SWCNTs) were investigated. The grafted fillers acted as nucleating agents, increasing the crystallization temperature and degree of crystallinity of the matrix. They also enhanced its thermal stability, flame retardancy, glass transition $\left(T_{\mathrm{g}}\right)$ and heat deflection temperatures while reduced the coefficient of thermal expansion at temperatures below $T_{g}$. A strong rise in the thermal conductivity, Young's modulus and tensile strength was found with increasing filler loading both in the glassy and rubbery states. All these outstanding improvements are ascribed to strong matrix-filler interfacial interactions combined with a compatibilization effect that results in very homogeneous SWCNT dispersion. The results herein offer useful insights towards the development of engineering thermoplastic/CNT nanocomposites for high-temperature applications.
\end{abstract}

\section{Introduction}

One of the most important engineering thermoplastics is poly(phenylene sulphide) (PPS), a semicrystalline aromatic polymer composed of phenyl rings linked with sulphur atoms that possesses outstanding thermal and mechanical properties. It exhibits high decomposition temperature, good chemical, oxidation and flame resistance as well as high dimensional stability, minimum water absorption, anti-ageing and exceptional friction properties [1]. In addition, its low ionic content makes it an excellent electrical insulator. Extensive study has been carried out on this polymer. Several review articles covered most of the research topics about this material from synthesis and processing to characterization and modelling $[2,3]$. It is widely applied in many industrial fields, including the chemical, pharmaceutical, food, petroleum, electronics, automobile and aircrafts sectors. However, PPS has some limitations for certain applications requiring superior flame resistance, high glass transition temperature, strength or/and toughness. The addition of nanofillers into this thermoplastic is an attractive strategy to obtain composites with improved performance. For this purpose, different inorganic nanoparticles such as fullerene-like

\footnotetext{
* Corresponding author. Tel.: +34 91 562290; fax: +34 915644853.

E-mail address: adiez@ictp.csic.es (A.M. Díez-Pascual).
}

tungsten disulphide $\left(\mathrm{IF}_{-}-\mathrm{WS}_{2}\right.$ ) [4,5], $\mathrm{Al}_{2} \mathrm{O}_{3}[6] \mathrm{TiO}_{2}, \mathrm{ZnO}$, and $\mathrm{SiC}$ [7] have been melt-blended with PPS matrix.

Over the past few years, integration of carbon nanotubes (CNTs) with excellent properties into polymers has become a greatly appealing route for fabricating advanced multifunctional materials [8]. One of the main advantages of using CNTs as fillers is their enormous surface area (several orders of magnitude larger than that of conventional fillers) that leads to an improved filler-matrix interfacial adhesion, a key factor to attain effective enhancement in the final properties of the composites. However, their huge surface area is also responsible for the strong tendency of the CNTs to form agglomerates that makes very difficult their dispersion within the matrix. To overcome these inconveniences, various methods have been developed, such as the modification of CNTs through covalent or non-covalent approaches [9]. The covalent bonding (grafting) of polymer chains to the CNT surface is the most preferred since results in strong polymer-CNT interfacial adhesion, hence large interfacial shear strength [10]. Further, the chemical nature of the anchored functional groups can generate a compatibilizing effect, thus improving the CNT dispersion in the polymer matrix; therefore, the properties of these nanocomposites are superior to those containing pristine CNTs.

Recently, a few works have been published on the preparation and characterization of PPS based composites incorporating pristine CNTs using conventional techniques such as compression 
[11,12], extrusion [13-15] or injection moulding [16]. Although these studies reported some improvements in the mechanical, electrical and wear performances, they were far below the expectations. More significant enhancements in the physical properties of this thermoplastic were found using non-covalent functionalization strategies such as the wrapping with polyetherimide [17-19] or maleimide polymers [20]. A more effective way to attain improved performance would be the formation of covalent linkages at the CNT-PPS interface; however, the insolubility of this polymer in common organic solvents and its lack of terminal end groups make difficult its functionalization, hence the grafting to other molecules. Therefore, studies dealing with the development of PPS/CNT nanocomposites through the covalent route are very scarce.

In a previous study [21], an aminated polymer derivative (PPS$\mathrm{NH}_{2}$ ) was covalently grafted onto the surface of acid-functionalized single-walled carbon nanotubes (SWCNT-COOH), and the experimental results demonstrated remarkable enhancements in the storage modulus, glass transition temperature and electrical conductivity of the polymer with the grafting process. The main aim of the present work is to investigate the effect of PPS- $\mathrm{NH}_{2}$-gSWCNT as fillers in a PPS matrix, particularly on the thermal and thermomechanical behaviour, comparing the results with those obtained for reference composites reinforced directly with the same amounts of acid-treated SWCNTs. The study of the thermal properties of PPS/PPS- $\mathrm{NH}_{2}$-g-SWCNT nanocomposites such as crystallization behaviour, thermal stability, thermal conductivity and flame retardant performance is of a great interest for high-temperature applications as well as those requiring superior flame resistance or effective dissipation of accumulated heat. On the other hand, a detailed analysis of their thermomechanical properties including the glass transition temperature, coefficient of linear thermal expansion and heat deflection temperature is crucial for the design of nanocomposite structures where high dimensional stability and/or low distortion under load and temperature are required.

\section{Experimental}

\subsection{Materials}

PPS (Fortron 0205B4, $d_{25^{\circ} \mathrm{C}}=1.35 \mathrm{~g} / \mathrm{cm}^{3}, T_{\mathrm{g}} \sim 90^{\circ} \mathrm{C}, T_{\mathrm{m}} \sim 280^{\circ} \mathrm{C}$ ) was kindly provided by Ticona in powder form. The polymer was dried at $100{ }^{\circ} \mathrm{C}$ for $14 \mathrm{~h}$ and stored in a dry environment before blending. The aminated derivative (PPS- $\mathrm{NH}_{2}$ ) was synthesized from a nitrated PPS polymer using sodium dithionite $\left(\mathrm{Na}_{2} \mathrm{~S}_{2} \mathrm{O}_{4}\right)$ as reduction agent [22]. CVD SWCNTs $\left(d_{25{ }^{\circ} \mathrm{C}}=2.1 \mathrm{~g} / \mathrm{cm}^{3}\right.$, diameter: $1-2 \mathrm{~nm}$, length: $5-30 \mu \mathrm{m}$, amorphous carbon content $\leqslant 3 \mathrm{wt} \%$, purity $>90 \%$ ) were supplied by Cheap Tubes Inc, USA. They were oxidized in $\mathrm{HNO}_{3} 6 \mathrm{M}$ at $120^{\circ} \mathrm{C}$ for $4 \mathrm{~h}$ leading to acid-treated SWCNTs, and their functionalization degree $(\sim 7.1 \%)$ was determined from $T_{\mathrm{g}} \mathrm{A}$ analysis. A detailed description of the grafting process of PPS- $\mathrm{NH}_{2}$ onto the SWCNT-COOH is given elsewhere $[21,23]$.

\subsection{Preparation of PPS based nanocomposites}

PPS- $\mathrm{NH}_{2}$-g-SWCNT was initially mixed with the PPS powder by mechanical stirring and bath ultrasonication for approximately $30 \mathrm{~min}$, and subsequently dried in vacuum at $50^{\circ} \mathrm{C}$. PPS/PPS$\mathrm{NH}_{2}$-g-SWCNT nanocomposites with effective SWCNT contents in the range of $0.1-1.0 \mathrm{wt} \%$ were then prepared via melt-blending using a Haake Rheocord 90 extruder with counter-rotating screws. The rotor speed was set to $150 \mathrm{rpm}$ and the processing temperature was kept constant at $320^{\circ} \mathrm{C}$, with a mixing time of $20 \mathrm{~min}$. For comparative purposes, similar nanocomposites reinforced directly with the acid-treated SWCNTs were fabricated in the same way. Homogeneous films were manufactured by hot-compression at $320^{\circ} \mathrm{C}$ under successive pressure dwells of 5, 30 and 130 bars for $5 \mathrm{~min}$ at each pressure stage.

\subsection{Characterization techniques}

Scanning electron microscopy (SEM) images from cryo-fractured surfaces of the composites were obtained with a Philips XL30 microscope applying an acceleration voltage of $25 \mathrm{kV}$ and an intensity of $9 \times 10^{-9} \mathrm{~A}$.

Differential scanning calorimetry (DSC) experiments were carried out on a Mettler TA4000 differential scanning calorimeter, operating under nitrogen flow. Samples of $\sim 12 \mathrm{mg}$ placed in aluminium pans were melted at $320^{\circ} \mathrm{C}$ and kept at this temperature for $5 \mathrm{~min}$ to erase their thermal history. Subsequently, they were cooled from the melt to room temperature and then heated again up to $320^{\circ} \mathrm{C}$ at a scan rate of $10^{\circ} \mathrm{C} / \mathrm{min}$. The degree of crystallinity $\left(X_{c}\right)$ was estimated according to the relation: $X_{c}=\Delta H_{\mathrm{m}} /\left(\Delta H_{\mathrm{m}}^{\circ}, \times w_{\mathrm{m}}\right)$, where $\Delta H_{\mathrm{m}}^{\circ}$, is the heat of fusion for a $100 \%$ crystalline PPS taken as $80 \mathrm{~J} / \mathrm{g}$ [24], $\Delta H_{\mathrm{m}}$, is the apparent melting enthalpy and $w_{\mathrm{m}}$ the weight fraction of the matrix.

Thermogravimetric analysis (TGA) experiments were conducted in a Mettler TA-4000/TG-50 thermobalance at a heating rate of $20^{\circ} \mathrm{C} / \mathrm{min}$. The temperature was scanned from 100 to $900{ }^{\circ} \mathrm{C}$ under both oxidizing (air) and inert (nitrogen) atmospheres. Measurements were performed on samples of $\sim 20 \mathrm{mg}$ with a purge gas flow rate of $50 \mathrm{ml} / \mathrm{min}$.

Tensile tests were carried out on a servo-hydraulic testing machine (type MTS 858) equipped with a temperature control system, using a crosshead speed of $1 \mathrm{~mm} / \mathrm{min}$ and a load cell of $100 \mathrm{kN}$, in the temperature range between 0 and $200^{\circ} \mathrm{C}$, at $50 \pm 5 \% \mathrm{RH}$. Experiments were performed according to the ASTM D638 standard. All the samples were conditioned for $24 \mathrm{~h}$ before the measurements. 5 coupons were tested for each sample, and the data reported correspond to the average value.

The heat release rate (HRR) was obtained by pyrolysis combustion flow calorimetry on samples of $\sim 10 \mathrm{mg}$. Prior to the measurements, samples were conditioned at $25 \pm 2{ }^{\circ} \mathrm{C}$ and $50 \pm 5 \%$ RH for 1 week. Experiments were carried out in a nitrogen stream at a heating rate of $60^{\circ} \mathrm{C} / \mathrm{min}$; the maximum pyrolysis temperature was $900^{\circ} \mathrm{C}$. The decomposition products were mixed with excess oxygen and completely oxidized at high temperature. The HRR was determined by oxygen consumption calorimetry. All the composites were tested in triplicate to ensure good reproducibility.

The effective thermal conductivity $(\lambda)$ was determined with a KES-F7 Thermo Labo type II equipment. The device is equipped with a temperature controlled hot plate, and is placed in a thermostatic chamber to be kept in a constant operating environment. The effect of the contact thermal resistance was removed by measuring the thermal conductivity of a reference material. $\lambda$ was calculated using the equation $\lambda=t W /\left(T_{\text {hot }}-T_{\text {cold }}\right) A$, where $t$ is the sample thickness, $W$ is the heat flow, $T_{\text {hot }}$ and $T_{\text {cold }}$ are the temperatures of the hot and cold plates, respectively, and $A$ is the surface area of the hot plate $\left(2.5 \times 2.5 \mathrm{~mm}^{2}\right)$. 5 specimens for each composite were tested and the average value is reported.

The coefficient of thermal expansion (CTE) was measured using a Perkin-Elmer TMA 7 thermomechanical analyzer. Samples of $\sim 7 \mathrm{~mm} \times 7 \mathrm{~mm}$ size were heated from 0 to $200^{\circ} \mathrm{C}$ at rate of $2{ }^{\circ} \mathrm{C} /$ min under a nitrogen atmosphere. $T_{\mathrm{g}}$ was identified as the temperature at which the slope of the TMA plot changed, and the CTE was determined both below and above $T_{\mathrm{g}}$.

Heat distortion temperature (HDT) was measured according to ASTM D648 standard using a TA 2980 DMA tester. Samples were conditioned at $25 \pm 2{ }^{\circ} \mathrm{C}$ and $50 \pm 5 \% \mathrm{RH}$ for $48 \mathrm{~h}$ prior to the measurements. A constant load of $1.8 \mathrm{MPa}$ was applied at the centre of 
the specimens, which were heated from room temperature to $250^{\circ} \mathrm{C}$ at a rate of $2{ }^{\circ} \mathrm{C} / \mathrm{min}$, and the sample deflection was recorded as a function of temperature.

\section{Results and discussion}

\subsection{Thermal properties}

\subsubsection{Crystallization and melting behaviour}

The crystallization process plays a key role on the properties of semicrystaline polymeric materials, since it conditions not only the crystalline structure and morphology but also their ultimate physical properties. Contradictory observations related to the crystallization behaviour of PPS/CNT nanocomposites have been described in the literature. Wu et al. [15] found a progressive rise in the peak crystallization temperature $\left(T_{\mathrm{c}}\right)$ upon increasing the amount of multi-walled carbon nanotubes (MWCNTs) and Yang et al. [13] described an increase at low loadings until a constant saturating value was attained, whereas Yu et al. [16] observed a progressive downshift. A small decrease in $T_{\mathrm{c}}$ was also reported for composites including acid-purified SWCNTs wrapped in polyetherimide (PEI) as a compatibilizing agent [17]. These discrepancies confirm that factors such as the CNT type, aspect ratio, purity, degree of dispersion and interfacial adhesion with the matrix, amongst others, have strong influence on the organization of the polymeric chains into crystalline arrangements. Therefore, a detailed investigation should be carried out in order to elucidate the effect of each type of nanotube on the crystallization process of the matrix, aimed at correlating the microscopic structure with macroscopic properties.

Typical non-isothermal melting and crystallization thermograms for neat PPS and nanocomposites with $0.1,0.5$ and $1.0 \mathrm{wt} \%$ nanotube loading are displayed in Fig. 1. Neat PPS shows a $T_{\mathrm{c}}$ of around $2466^{\circ} \mathrm{C}$, and it decreases gradually with increasing the amount of acid-treated SWCNTs, by up to $7{ }^{\circ} \mathrm{C}$ at $1.0 \mathrm{wt} \%$ loading. Similar decreasing trend is found for the onset crystallization temperature $\left(T_{\text {c-onset }}\right)$, the crystallization enthalpy $\left(\Delta H_{\mathrm{c}}\right)$ and the degree of crystallinity $\left(X_{c}\right)$, as listed in Table 1 . The peak melting temperature $\left(T_{\mathrm{m}}\right)$ also decreased slightly, indicative of a faster crystallization process that leads to the formation of smaller and less perfect crystals. Further, the degree of supercooling ( $\left.\Delta T=T_{\mathrm{m}}-T_{\text {c-onset }}\right)$ increases with the addition of these SWCNTs, indicative of a decelerated nucleation process. However, a completely different behaviour can be observed for nanocomposites incorporating grafted fillers. Thus, for low contents of PPS- $\mathrm{NH}_{2}$-g-SWCNTs (nanotube loading $\leqslant 0.5 \mathrm{wt} \%$ ), a clear rise in all the above mentioned parameters except in $\Delta T$ is observed, particularly in $T_{\mathrm{c}}$ (up to $9{ }^{\circ} \mathrm{C}$ at $0.5 \mathrm{wt} \%$ ), while for higher concentrations they take approximately the same values as those of the neat polymer. Generally, the addition of CNTs to polymers results in two opposite effects on the crystallization behaviour of the matrix that compete against each other. On the one hand, they act as heterogenous nucleating sites, thereby increasing the crystallization rate. On the other hand, they impose a confinement on the diffusion and arrangement of the polymer chains and hence delay the overall crystallization process. This confinement effect is attributed to the development of an entangled CNT network at high nanofiller contents [25], where the CNT-CNT contact is more likely. Regarding the non-grafted SWCNTs, they do not exert a macroscopic nucleating effect due to poor dispersion, thus $T_{\mathrm{c}}$ and $X_{\mathrm{c}}$ decrease for all the compositions studied. In the case of nanocomposites with grafted fillers, a significant dependence on the CNT concentration is found. When a minor content is incorporated in the PPS matrix the nucleating effect prevails, ascribed to a very homogenous dispersion (as demonstrated by SEM images, Fig. 2) arising from an enhanced filler-matrix compatibility that would lead to more nuclei crystallizable per


Fig. 1. DSC heating (top) and cooling (bottom) thermograms for neat PPS and nanocomposites with different SWCNT loading. (For interpretation of the references to colour in this figure legend, the reader is referred to the web version of this article.)

unit volume of polymer, hence higher crystallinity. This is also consistent with the higher $T_{\mathrm{m}}$ observed for these nanocomposites, thus slower crystallization process that provides longer time for the crystal growth. In contrast, at higher loadings, the covalent grafting leads to a strong confinement of the PPS chains that compensates for the nucleating effect; overall, $T_{c}$ and $X_{c}$ are almost the same as those of the neat matrix. The differences between the two types of nanocomposites are more significant in terms of the degree of crystallinity: 1.0 wt\% grafted SWCNTs leads to an $8 \%$ increase in $X_{c}$ of the matrix, while the direct incorporation of the same amount of nanofillers results in a $17 \%$ fall. This discrepancy would also influence on their mechanical behaviour; the rise in crystallinity observed in PPS/PPS- $\mathrm{NH}_{2}$-g-SWCNT nanocomposites would impart stronger improvements in mechanical properties such as tensile parameters, as will be discussed in a following section. It is worthy to note that the melting behaviour of PPS remains merely unchanged upon addition of both types of fillers (differences in $T_{\mathrm{m}}$ $\leqslant 4^{\circ} \mathrm{C}$ ), which is important from an industrial viewpoint because no additional energy would be required for further processing these nanocomposites (i.e. when using them as matrices for the development of multiscale fibre-reinforced laminates). From DSC scans it was difficult to determine the glass transition temperature $\left(T_{\mathrm{g}}\right)$ of the nanocomposites, which was accurately measured by TMA (Section 3.2.1).

\subsubsection{Thermal stability and flammability}

Thermogravimetric analysis was carried out in order to test the influence of both types of fillers on the thermal stability of PPS. The 
Table 1

DSC parameters obtained from the heating and cooling thermograms of PPS/SWCNT and PPS/PPS-NH $\mathrm{N}_{2}-\mathrm{g}-\mathrm{SWCNT}$ nanocomposites.

\begin{tabular}{|c|c|c|c|c|c|c|c|c|}
\hline Material (SWCNT content) & $\Delta H_{\mathrm{m}}(\mathrm{J} / \mathrm{g})$ & $T_{\mathrm{m}}\left({ }^{\circ} \mathrm{C}\right)$ & $T_{\mathrm{m} \text {-onset }}\left({ }^{\circ} \mathrm{C}\right)$ & $\Delta H_{c}(\mathrm{~J} / \mathrm{g})$ & $T_{\mathrm{c}}\left({ }^{\circ} \mathrm{C}\right)$ & $T_{\mathrm{c} \text {-onset }}\left({ }^{\circ} \mathrm{C}\right)$ & $\Delta T\left({ }^{\circ} \mathrm{C}\right)$ & $X_{c}(\%)$ \\
\hline PPS & $42 \pm 1$ & $278 \pm 1$ & $253 \pm 1$ & $-39 \pm 1$ & $247 \pm 1$ & $256 \pm 1$ & $22 \pm 2$ & $52 \pm 1$ \\
\hline PPS/SWCNT (0.1 wt\%) & $40 \pm 2$ & $278 \pm 1$ & $254 \pm 2$ & $-38 \pm 1$ & $244 \pm 1$ & $255 \pm 1$ & $23 \pm 2$ & $50 \pm 2$ \\
\hline PPS/SWCNT (0.5 wt\%) & $38 \pm 1$ & $277 \pm 1$ & $251 \pm 2$ & $-37 \pm 1$ & $242 \pm 1$ & $253 \pm 2$ & $24 \pm 3$ & $47 \pm 1$ \\
\hline PPS/SWCNT (1.0 wt\%) & $34 \pm 1$ & $275 \pm 1$ & $247 \pm 1$ & $-35 \pm 1$ & $240 \pm 1$ & $253 \pm 1$ & $27 \pm 2$ & $44 \pm 1$ \\
\hline PPS/PPS-NH ${ }_{2}$-g-SWCNT (0.1 wt\%) & $44 \pm 2$ & $281 \pm 1$ & $256 \pm 2$ & $-44 \pm 2$ & $254 \pm 1$ & $263 \pm 2$ & $18 \pm 3$ & $55 \pm 2$ \\
\hline PPS/PPS-NH ${ }_{2}-g-S W C N T(0.5$ wt\%) & $45 \pm 2$ & $282 \pm 1$ & $257 \pm 2$ & $-43 \pm 1$ & $256 \pm 1$ & $263 \pm 1$ & $19 \pm 2$ & $57 \pm 2$ \\
\hline PPS/PPS-NH ${ }_{2}-g-S W C N T(1.0$ wt\%) & $42 \pm 1$ & $279 \pm 1$ & $254 \pm 1$ & $-41 \pm 2$ & $249 \pm 1$ & $258 \pm 1$ & $21 \pm 2$ & $53 \pm 1$ \\
\hline
\end{tabular}

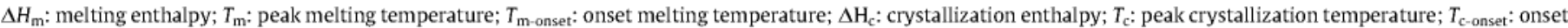
crystallization temperature; $X_{\mathrm{c}}$ : degree of crystallinity; $\Delta T$ : degree of supercooling $=T_{\mathrm{m}}-T_{\mathrm{c} \text {-onset- }}$.
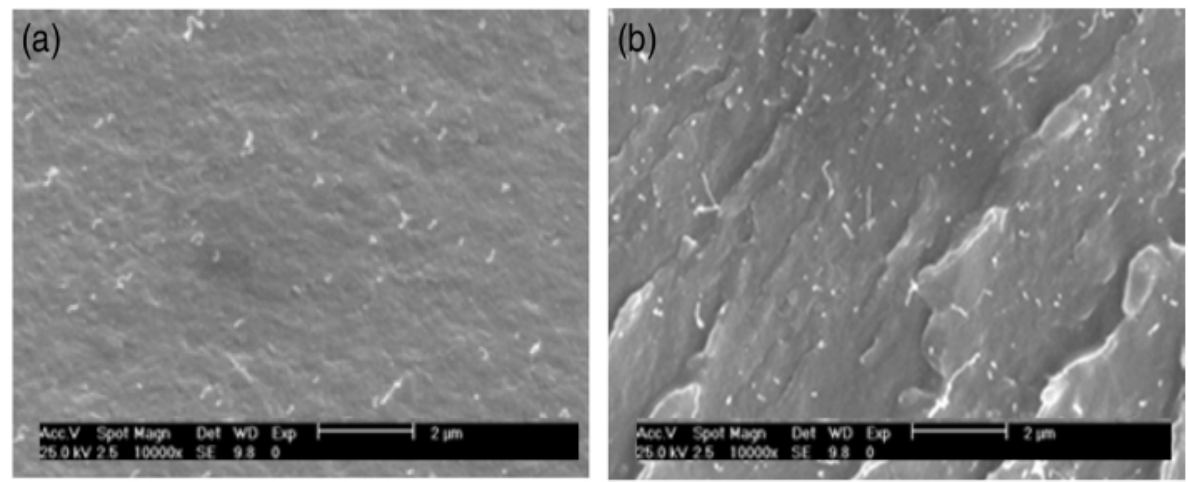

Fig. 2. SEM images of PPS/PPS-NH $\mathrm{N}_{2}$-g-SWCNT nanocomposites with effective SWCNT contents of (a) 0.1 and (b) 0.5 wt $\%$.

TGA curves for the neat matrix and nanocomposites with various nanotube loadings under both oxidizing and inert atmospheres are shown in Fig. 3 and their characteristic degradation temperatures are summarized in Table 2. Clearly, the addition of these fillers leads to an improvement in the thermal stability of the matrix, and the effect of PPS- $\mathrm{NH}_{2}$-g-SWCNTs surpasses that caused by the direct incorporation of the SWCNTs under both environments. In nitrogen atmosphere, where the decomposition takes place in a single degradation stage for all the samples studied, a maximum increase in the initial degradation temperature $\left(T_{i}\right)$ of about $20^{\circ} \mathrm{C}$ is attained at $1.0 \mathrm{wt} \%$ loading of grafted fillers, whereas for the same concentration of non-grafted SWCNTs the increment is only $\sim 7^{\circ} \mathrm{C}$, which is comparable to that reported by Yu et al. [16] for 2 wt\% loading of bare MWCNTs. Analogous trends are found for the temperature of $10 \%$ weight loss $\left(T_{10}\right)$ and the temperature of maximum rate of weight loss $\left(T_{\max }\right)$, where the increments for $1.0 \mathrm{wt} \%$ grafted SWCNTs are about 20 and $30^{\circ} \mathrm{C}$, while for the same content of non-grafted SWCNTs are 8 and $11^{\circ} \mathrm{C}$, respectively. The degradation process seems to be more complex in the presence of oxygen due to the overlapping of two degradation steps that lead to the total decomposition of the materials. Again, the incorporation of PPS- $\mathrm{NH}_{2}$-g-SWCNTs induces a remarkable thermal stabilization of the matrix, with increases in $T_{i}$ and $T_{\max }$ by up to 23 and $35{ }^{\circ} \mathrm{C}$ at $1.0 \mathrm{wt} \%$ effective loading, whereas the direct addition of the same amount of SWCNTs leads to smaller increments, on average $12^{\circ} \mathrm{C}$. It is important to highlight that the improvements in thermal stability attained in the grafted composites are significantly larger than those reported in the literature for other PPS/ CNT nanocomposites $[16,17,26]$, yet another evidence of the potential of these fillers to be employed as reinforcement in composite materials for high-temperature applications. Such magnitude of enhancement should be attributed to different factors. Firstly, due to the high compatibility between the aminated derivative and the parent PPS, the grafted fillers are better dispersed within the matrix, and effectively hamper the diffusion of the degradation products from the bulk of the polymer to the gas phase, hence slowing down the decomposition process. Secondly, the covalent anchoring of the polymer segments to the SWCNTs strongly restricts chain mobility, thereby increasing the barrier effect. Moreover, it has been reported [27] that the thermal interfacial resistance nanotube-polymer decreases in the presence of chemical bonding, leading to a strong enhancement in the thermal conductivity (as will be shown in the following section) that facilitates heat dissipation within the composite. Previous studies $[28,29]$ also found larger thermal stability improvements for composites reinforced with polymer-grafted CNTs in comparison to those including pristine nanotubes.

On the other hand, the char residues under inert atmosphere have a very important implication in the flame retardant ability of the materials since they can be correlated with the Oxygen Index (OI) through the equation developed by van Krevelen [30]: $\mathrm{OI} \times 100=17.5+0.4 C R$, where $C R$ is the char residue in wt\% at $850^{\circ} \mathrm{C}$. The limiting $\mathrm{OI}$ is defined as the minimum amount of oxygen in a nitrogen-oxygen mixture that is just sufficient to maintain combustion after ignition. A material is considered flammable when $\mathrm{OI} \leqslant 26 \%$. The incorporation of progressive amounts of grafted SWCNTs leads to a gradual increase in the OI parameter of PPS, from $37 \%$ to $39 \%$ at 1.0 wt\% effective loading, while for composites directly reinforced with the SWCNTs the increments are notably smaller.

To further assess the influence of these fillers on the flammability behaviour of PPS in the nanocomposites, which is highly interesting for potential use in enclosed spaces such as automobiles, ships or aircrafts, their heat release curves were obtained from pyrolysis combustion flow calorimetry (Fig. 4), and the data derived from the tests are summarized in Table 3. As expected, neat PPS begins to release heat prior to all the nanocomposites, consistent with its lower thermal stability as revealed by TGA. The addition of grafted SWCNTs leads to a significant drop in the average peak heat release rate (PHRR), and the greatest reduction ( $23 \%)$ 

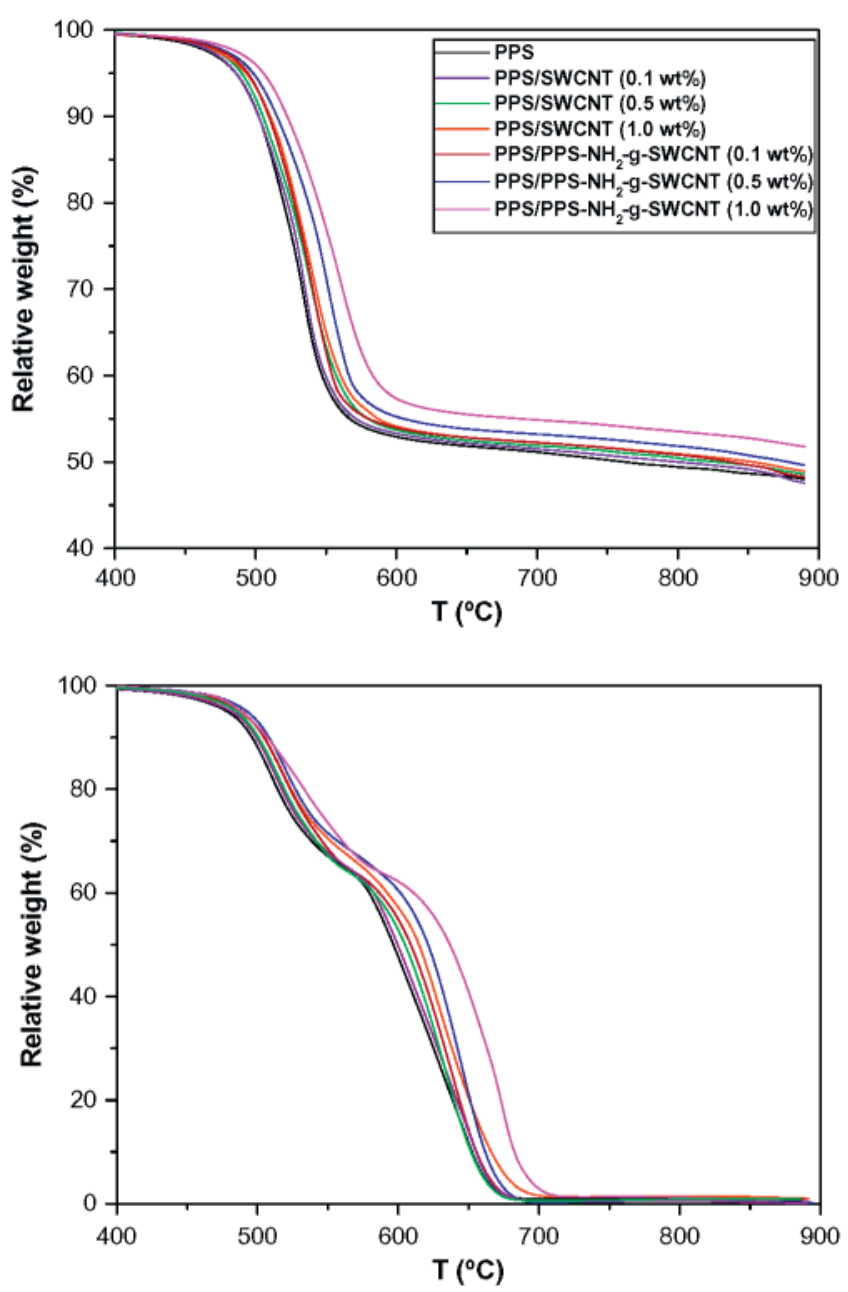

Fig. 3. TGA thermograms under inert (top) and oxidative (bottom) atmospheres for PPS based nanocomposites. For comparative purposes, only the temperature range between 400 and $900^{\circ} \mathrm{C}$ is plotted. (For interpretation of the references to colour in this figure legend, the reader is referred to the web version of this article.)

is found at $1.0 \mathrm{wt} \%$ effective loading. In contrast, for the PPS/ SWCNT nanocomposite with the same nanotube content the diminution is merely $11 \%$. The onset temperature at which begins the release of heat corresponds to the incipient ignition temperature (flashpoint) of PPS, while the temperature at PHRR corresponds to the continuous ignition (steady burning) temperature [30]. Both temperatures rise progressively with the SWCNT content, the largest increases being 15 and $31^{\circ} \mathrm{C}$, respectively, at $1.0 \mathrm{wt} \%$ loading of grafted fillers, while for the nanocomposite incorporating the same

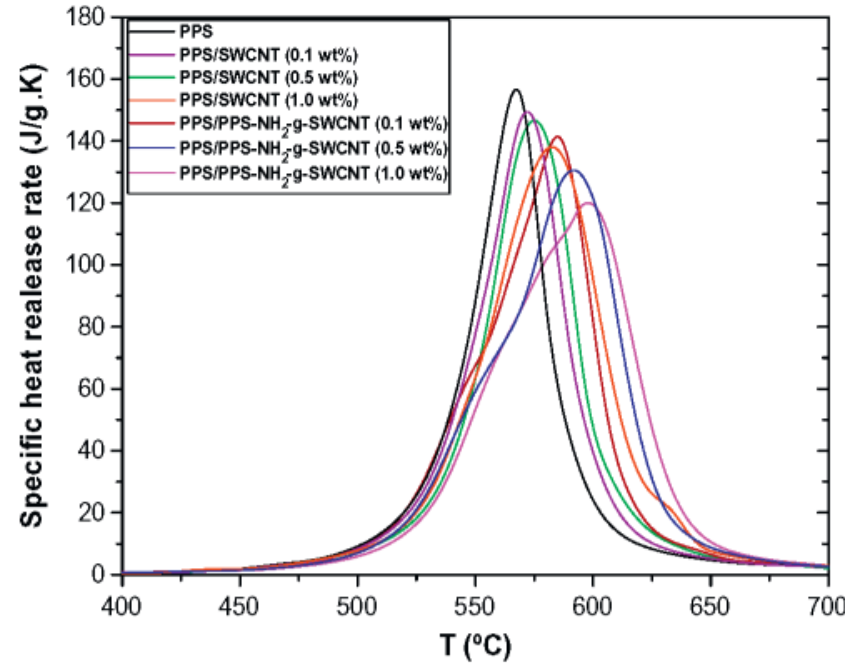

Fig. 4. Heat release curves obtained from pyrolysis combustion flow calorimetry for neat PPS and nanocomposites with different SWCNT loading. (For interpretation of the references to colour in this figure legend, the reader is referred to the web version of this article.)

amount of non-grafted SWCNTs the increases are about half of the aforementioned increments. These results confirm that the state of CNT dispersion strongly affects the flame retardant performance of the nanocomposites, as previously demonstrated for MWCNT-reinforced polypropylene (PP) [31] and polyamide-6 (PA-6) composites [32]: the development of a uniform CNT network-structured layer covering the entire sample surface seems to be crucial for efficiently reducing the flammability of the matrix [31]. When the sample reaches the decomposition temperature of the polymer, the matrix starts to degrade and recedes deeper into the nanocomposite, leaving a thick CNT layer on the surface. This layer acts as a radiation emitter from the surface back into the gas phase, thus reducing the transmitted flux to the polymer layers located below, hence slowing the pyrolysis rate. Regarding PPS/SWCNT nanocomposites, the nanotubes are gathered in certain regions and do not form a uniform network, hence they do not act effectively as a radiation shield, and consequently lead to a smaller fall in the PHRR in comparison to the grafted fillers that are homogenously dispersed within the matrix. Besides, the strong improvements attained in these nanocomposites should also be related to their enhanced thermal conductivity, as will be discussed below. Well-dispersed CNTs help to dissipate the heat quickly through the bulk of the composite, which means that it takes longer for the surface temperature to reach the onset and PHRR temperatures. Another plausible explanation for the improved flame retardancy could be that the nanotubes act as a mass transport barrier that hinder the

Table 2

Thermogravimetric data under inert and oxidative atmospheres for neat PPS and the nanocomposites.

\begin{tabular}{|c|c|c|c|c|c|c|c|c|}
\hline \multirow[t]{2}{*}{ Material (SWCNT content) } & \multicolumn{5}{|c|}{ Inert atmosphere } & \multicolumn{3}{|c|}{ Oxidative atmosphere } \\
\hline & $T_{i}\left({ }^{\circ} \mathrm{C}\right)$ & $T_{10}\left({ }^{\circ} \mathrm{C}\right)$ & $T_{\max }\left({ }^{\circ} \mathrm{C}\right)$ & $\mathrm{CR}_{850}(\%)$ & Ol $(\%)$ & $T_{\mathrm{i}}\left({ }^{\circ} \mathrm{C}\right)$ & $T_{10}\left({ }^{\circ} \mathrm{C}\right)$ & $T_{\max \text { I, Il }}\left({ }^{\circ} \mathrm{C}\right)$ \\
\hline PPS & $458 \pm 1$ & $503 \pm 1$ & $540 \pm 2$ & $48.7 \pm 0.3$ & $37.0 \pm 0.1$ & $447 \pm 1$ & $497 \pm 1$ & $507 \pm 2,628 \pm 1$ \\
\hline PPS/SWCNT (0.1 wt\%) & $458 \pm 1$ & $503 \pm 1$ & $542 \pm 1$ & $49.0 \pm 0.5$ & $37.1 \pm 0.2$ & $449 \pm 1$ & $500 \pm 1$ & $510 \pm 1,629 \pm 2$ \\
\hline PPS/SWCNT (0.5 wt\%) & $463 \pm 1$ & $506 \pm 1$ & $547 \pm 2$ & $49.6 \pm 0.4$ & $37.3 \pm 0.2$ & $456 \pm 1$ & $503 \pm 1$ & $513 \pm 1,634 \pm 2$ \\
\hline PPS/SWCNT (1.0 wt\%) & $465 \pm 1$ & $511 \pm 1$ & $551 \pm 1$ & $50.2 \pm 0.1$ & $37.6 \pm 0.1$ & $459 \pm 1$ & $507 \pm 1$ & $517 \pm 2,640 \pm 3$ \\
\hline PPS/PPS-NH - -g-SWCNT (0.1 wt\%) & $466 \pm 1$ & $506 \pm 1$ & $548 \pm 1$ & $49.8 \pm 0.2$ & $37.4 \pm 0.1$ & $461 \pm 1$ & $504 \pm 1$ & $520 \pm 1,634 \pm 2$ \\
\hline PPS/PPS-NH - -g-SWCNT (0.5 wt\%) & $472 \pm 1$ & $514 \pm 1$ & $559 \pm 2$ & $51.5 \pm 0.4$ & $38.1 \pm 0.2$ & $468 \pm 1$ & $509 \pm 1$ & $524 \pm 2,646 \pm 2$ \\
\hline PPS/PPS-NH $\mathrm{N}_{2}-\mathrm{g}$-SWCNT (1.0 wt\%) & $479 \pm 1$ & $522 \pm 1$ & $571 \pm 2$ & $53.8 \pm 0.3$ & $39.0 \pm 0.1$ & $470 \pm 1$ & $511 \pm 1$ & $530 \pm 2,663 \pm 1$ \\
\hline
\end{tabular}

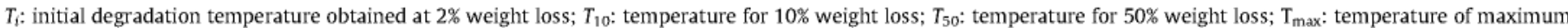
rate of weight loss; $\mathrm{CR}_{850}$ : char residue at $850^{\circ} \mathrm{C}$ and OI: Oxygen Index parameter. 
Table 3

Pyrolysis combustion flow calorimeter data for PPS based nanocomposites.

\begin{tabular}{|c|c|c|c|c|}
\hline Material (SWCNT content) & $\begin{array}{l}T_{\text {onset }} \\
\left({ }^{\circ} \mathrm{C}\right)\end{array}$ & $\begin{array}{l}T_{\mathrm{PHRR}} \\
\left({ }^{\circ} \mathrm{C}\right)\end{array}$ & $\begin{array}{l}\text { PHRR(W/ } \\
\text { g) }\end{array}$ & $\begin{array}{l}\text { Char residue } \\
(\%)\end{array}$ \\
\hline PPS & $519 \pm 1$ & $567 \pm 1$ & $156 \pm 5$ & $47.2 \pm 0.2$ \\
\hline PPS/SWCNT (0.1 wt\%) & $521 \pm 1$ & $572 \pm 2$ & $149 \pm 7$ & $47.4 \pm 0.4$ \\
\hline PPS/SWCNT (0.5 wt\%) & $525 \pm 2$ & $575 \pm 2$ & $146 \pm 5$ & $47.9 \pm 0.1$ \\
\hline PPS/SWCNT (1.0 wt\%) & $527 \pm 1$ & $581 \pm 1$ & $138 \pm 4$ & $48.6 \pm 0.5$ \\
\hline $\begin{array}{l}\text { PPS/PPS-NH }{ }_{2}-\mathrm{g}-\mathrm{SWCNT} \\
\quad(0.1 \mathrm{wt} \%)\end{array}$ & $520 \pm 1$ & $584 \pm 2$ & $141 \pm 6$ & $48.0 \pm 0.2$ \\
\hline $\begin{array}{l}\text { PPS/PPS-NH }-\mathrm{g}-\mathrm{SWCNT} \\
\quad(0.5 \mathrm{wt} \%)\end{array}$ & $528 \pm 2$ & $592 \pm 2$ & $130 \pm 5$ & $49.1 \pm 0.3$ \\
\hline $\begin{array}{l}\text { PPS/PPS-NH }- \text {-g-SWCNT } \\
\quad(1.0 \text { wt } \%)\end{array}$ & $534 \pm 1$ & $598 \pm 1$ & $120 \pm 4$ & $50.3 \pm 0.3$ \\
\hline
\end{tabular}

PHRR: peak heat release rate.

evolution of flammable volatiles generated during the decomposition process and also prevent oxygen from reaching the matrix. The grafted fillers should lead to a more confined geometry and enhanced network structure that increases this barrier effect. On the other hand, it has been argued that $\mathrm{T}_{10}$ in TGA under air atmosphere approximately corresponds to the incipient ignition temperature [33]. The differences found $\left(\leqslant 23^{\circ} \mathrm{C}\right)$ are probably due to the higher heating rate in the flammability tests. In contrast, the char residues obtained from both techniques (Tables 2 and 3) are in very good agreement. Given the low percentage of SWCNTs used in this study, the significant enhancements in thermal stability and flame retardancy attained make the PPS/PPS- $\mathrm{NH}_{2}$-g-SWCNT nanocomposites highly attractive for use in high-temperature applications.

\subsubsection{Thermal conductivity}

Strong interest exists in developing thermally conducting polymeric nanocomposites using CNTs to be employed in applications that require effective dissipation of accumulated heat such as connectors, printed circuit boards, heat sinks, chip carriers, switches and electrical components. The thermal conductivity $(\lambda)$ depends on several factors, namely the nanofiller purity, size, aspect ratio, concentration and state of dispersion as well as the nature, molecular weight, structural defects and degree of crystallinity of the polymer. $\lambda$ of PPS and the nanocomposites was measured as a function of temperature and the results are shown in Fig. 5 a. At $25^{\circ} \mathrm{C}, \lambda$ of the neat matrix is about $0.33 \mathrm{~W} / \mathrm{m} \mathrm{K}$, and increases steadily up to $T_{\mathrm{g}}$, while it decreases slightly at higher temperatures, ascribed to phonon scattering induced by changes in the amorphous region [12]. In the glassy state, $\lambda$ of all the nanocomposites rises almost linearly with temperature due to an increase in the phonon mean free path that enhances the phonon propagation length, which implies higher conductivity [34]. Further, the average slope rises gradually with the SWCNT concentration, from $4.11 \times 10^{-4} \mathrm{~W} /$ $\mathrm{m} \mathrm{K}$ for neat PPS to $8.78 \times 10^{-4}$ and $1.13 \times 10^{-3} \mathrm{~W} / \mathrm{m} \mathrm{K}$ for composites with 0.1 and $1.0 \mathrm{wt} \%$ grafted fillers, respectively, attributed to an increment in the phonon population. An analogous trend is found for PPS/SWCNT nanocomposites, albeit the increments in $d \lambda / d \mathrm{~T}$ are smaller. The different behaviour found for both types of nanocomposites probably arises from differences in the Kapitza resistance, the interfacial resistance to heat transfer between the CNTs and the surrounding matrix. The strong interfacial bonding achieved through the covalent grafting enhances the SWCNT-PPS coupling, thereby increasing the number of low-frequency vibrational modes at the interface, hence decreasing the Kapitza resistance. However, the temperature dependence of $\lambda$ changes when the matrix becomes less stiff in the vicinity of $T_{\mathrm{g}}$, and the slope in the rubbery state shows a significant reduction for all the nanocomposites, likely caused by a modification in the thermal trans-
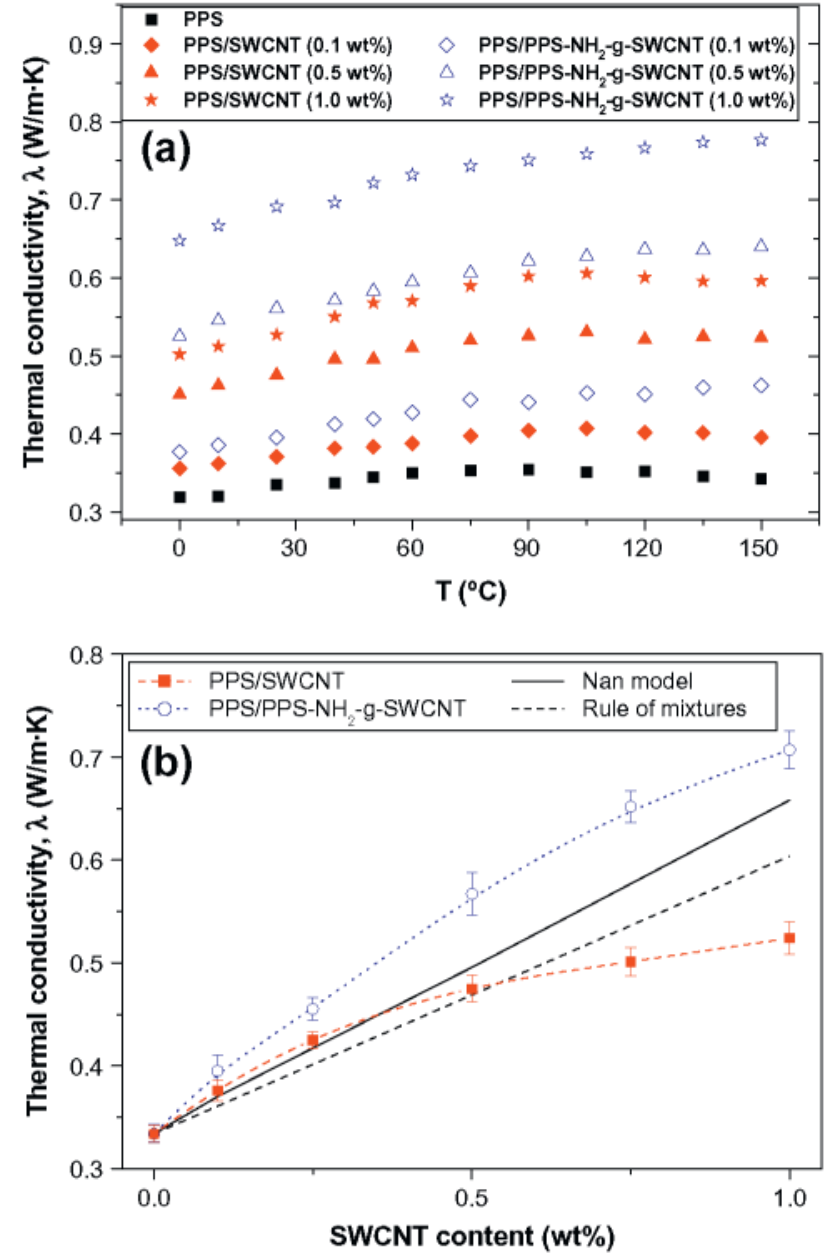

Fig. 5. (a) Thermal conductivity as a function of temperature for PPS based nanocomposites with different SWCNT loading. (b) Comparison of the room temperature thermal conductivity as a function of the SWCNT loading for the two types of nanocomposites investigated. The solid and dash straight lines represent the predictions by the model developed by Nan et al. and the modified rule of mixtures, respectively (see explanation in the text). (For interpretation of the references to colour in this figure legend, the reader is referred to the web version of this article.)

port. In fact, previous studies on polystyrene/SWCNT nanocomposites [35] indicated an increase in the Kapitza resistance at temperatures above $T_{\mathrm{g}}$. In this region, $\lambda$ slightly decreases with temperature for the nanocomposites with non-grafted SWCNTs whilst shows a very small increase for those with covalently grafted fillers that could be related to their differences in the degree of crystallinity (Table 1 ), since $\lambda$ of semicrystalline polymeric samples is known to increase with crystallinity [36]. Nevertheless, $\lambda$ should be strongly affected by the phonon scattering at the interface between the amorphous and crystalline phases.

In the whole temperature range studied, a significant increase in $\lambda$ is observed upon addition of the SWCNTs, particularly those covalently grafted to the aminated derivative that should arise from their much higher thermal conductivity compared to that of PPS combined with a very homogenous dispersion and a strong interfacial adhesion with the matrix chains that promotes the conduction of phonons at the interface and minimizes the coupling losses. This effect of $\lambda$ enhancement is greater at high temperatures; thus, for 1.0 wt\% grafted and non-grafted SWCNTs, $\lambda$ increments at $150{ }^{\circ} \mathrm{C}(\sim 125$ and $52 \%)$ are on average 30\% higher than those found at $0^{\circ} \mathrm{C}$. This trend is consistent with the results reported for other thermoplastic/CNT nanocomposites such as those 


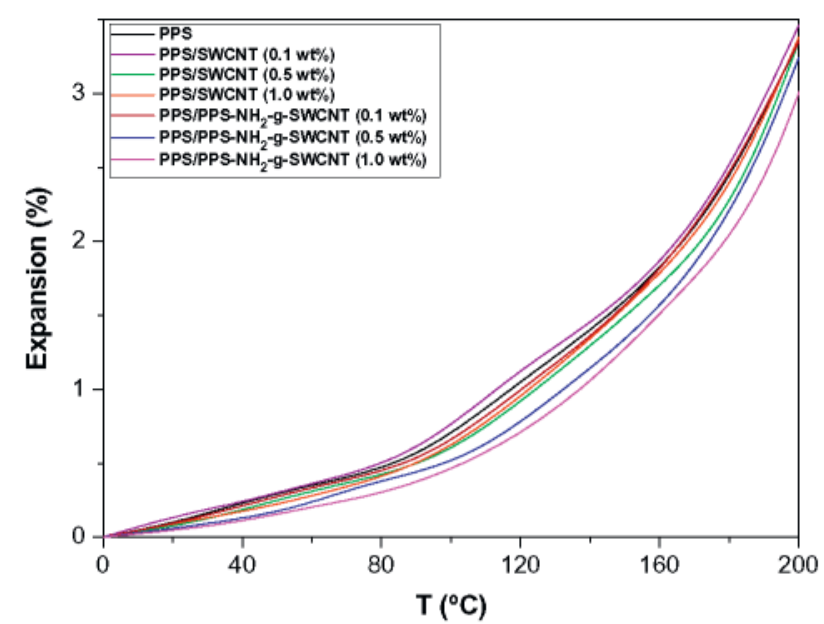

Fig. 6. TMA expansion curves for neat PPS and nanocomposites with various SWCNT contents. (For interpretation of the references to colour in this figure legend, the reader is referred to the web version of this article.)

based on PP [31] or poly(vinylidene fluoride) (PVDF) [37]. Fig. 5b plots the evolution of $\lambda$ at $25^{\circ} \mathrm{C}$ as a function of the SWCNT loading. A quasi linear increase is found for PPS/PPS- $\mathrm{NH}_{2}$-g-SWCNT nanocomposites, while those prepared by direct incorporation of the SWCNTs exhibit a strong deviation from the linearity for CNT contents $\geqslant 0.75 \mathrm{wt} \%$. Thus, the maximum $\lambda$ increments for the two types of nanocomposites are about $105 \%$ and $42 \%$, respectively. Note that the enhancements attained through the polymer grafting are considerably larger than those reported for other PPS/CNT nanocomposites $[17,20]$, thereby confirming the efficiency of the covalent functionalization employed for improving the composite conductivity.

Several models [36] have been reported to estimate $\lambda$ of polymer/CNT composites. The modified rule of mixtures for discontinuous reinforcement can provide a good approximation taking into account $\lambda$ reported for SWCNT bundles $(\sim 300 \mathrm{~W} / \mathrm{m} \mathrm{K}[38])$. It can be expressed as: $\lambda_{\mathrm{c}}=\eta_{1}^{2} \lambda_{\mathrm{f}} V_{\mathrm{f}}+\lambda_{\mathrm{m}}\left(1-V_{\mathrm{f}}\right)$, where $\lambda_{\mathrm{c}}, \lambda_{\mathrm{m}}$ and $\lambda_{\mathrm{f}}$ are the thermal conductivities of the composite, matrix and filler, respectively, $V_{\mathrm{f}}$ is the filler volume fraction and $\eta_{1}$ is the length efficiency factor that accounts for the waviness of the CNTs that was assumed to be 0.27 [39]. The theoretical values are plotted in Fig. 5b as a dashed line. Regarding PPS/SWCNT nanocomposites, the experimental values are in good agreement with those calculated by the model up to $0.5 \mathrm{wt} \%$, and then fall considerably below the predictions. However, for PPS/PPS- $\mathrm{NH}_{2}-\mathrm{g}-\mathrm{SWCNT}$, the measured data are systematically above the theoretical values. In addition, the model developed by Nan et al. [40] for randomly oriented CNTs in a composite was applied as follows: $\lambda_{\mathrm{c}}=\left[3 \lambda_{\mathrm{m}}+\eta_{\mathrm{l}}^{2} \lambda_{\mathrm{f}} V_{\mathrm{f}}\right] /\left(3-2 V_{\mathrm{f}}\right)$, where the aforementioned efficiency

Table 4

Thermomechanical properties for PPS and the different nanocomposites: Heat deflection temperature (HDT), glass transition temperature $\left(T_{\mathrm{g}}\right)$ and coefficient of linear thermal expansion (CTE).

\begin{tabular}{|c|c|c|c|c|}
\hline \multirow[t]{2}{*}{ Material (SWCNT content) } & \multirow[t]{2}{*}{ HDT $\left({ }^{\circ} \mathrm{C}\right)$} & \multirow[t]{2}{*}{$T_{g}\left({ }^{\circ} \mathrm{C}\right)$} & \multicolumn{2}{|c|}{ CTE $\left(10^{-6} /{ }^{\circ} \mathrm{C}\right)$} \\
\hline & & & $25^{\circ} \mathrm{C}$ & $120^{\circ} \mathrm{C}$ \\
\hline PPS & $110 \pm 1$ & $89 \pm 1$ & $58 \pm 2$ & $145 \pm 3$ \\
\hline PPS/SWCNT (0.1 wt\%) & $108 \pm 1$ & $90 \pm 2$ & $57 \pm 3$ & $146 \pm 5$ \\
\hline PPS/SWCNT (0.5 wt\%) & $115 \pm 2$ & $96 \pm 2$ & $54 \pm 2$ & $148 \pm 4$ \\
\hline PPS/SWCNT (1.0 wt\%) & $112 \pm 1$ & $95 \pm 3$ & $50 \pm 1$ & $149 \pm 5$ \\
\hline PPS/PPS-NH ${ }_{2}-\mathrm{g}-\mathrm{SWCNT}(0.1 \mathrm{wt} \%)$ & $114 \pm 1$ & $92 \pm 1$ & $55 \pm 2$ & $148 \pm 4$ \\
\hline PPS/PPS-NH ${ }_{2}-\mathrm{g}-\mathrm{SWCNT}(0.5 \mathrm{wt} \%)$ & $121 \pm 1$ & $103 \pm 3$ & $47 \pm 1$ & $152 \pm 4$ \\
\hline PPS/PPS-NH - -g-SWCNT (1.0 wt\%) & $126 \pm 2$ & $108 \pm 2$ & $42 \pm 1$ & $156 \pm 6$ \\
\hline
\end{tabular}
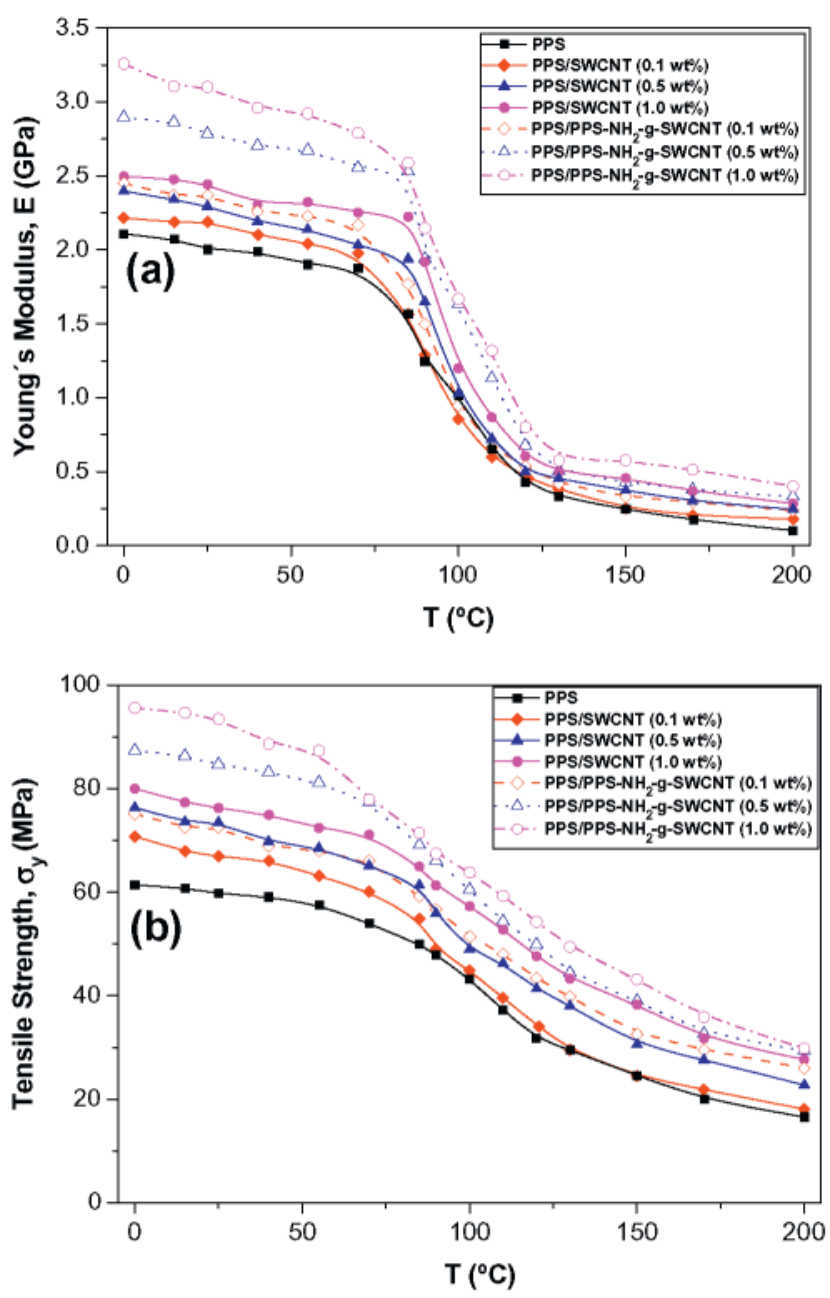

Fig. 7. Young's modulus (a) and tensile strength (b) as a function of temperature for PPS based nanocomposites. (For interpretation of the references to colour in this figure legend, the reader is referred to the web version of this article.)

factor was taken into account to obtain a more accurately fit for the experimental data. As can be observed (straight solid line in Fig. 5b), this model also describes satisfactorily the experimental behaviour of PPS/SWCNT at low filler contents, although shows a noticeable deviation at $1.0 \mathrm{wt} \%$. The poor filler dispersion and the small thermal conductance of the nanotube-polymer interface could explain the discrepancy found between the theoretical and the experimental data. In contrast, for all the concentrations studied, the predictions for composites with grafted fillers are slightly lower than the measured values (differences $\leqslant 12 \%$ ). Despite the large amount of CNT-CNT junctions in the nanotube network would hinder phonon movement hence limiting the heat transfer [36,41], this phenomenon appears to be outweighed by the improved CNT dispersion and reduced phonon scattering between the SWCNTs and the matrix due to the formation of covalent linkages at the interface, resulting in thermal conductivity values higher than those calculated by the models.

\subsection{Thermomechanical properties}

\subsubsection{Glass transition temperature}

The glass transition temperature $\left(T_{g}\right)$ is indicative of the motion of the polymer chains. In an unfilled system the chains are free from restraints. The addition of CNTs, which are dimensionally similar to the polymer segments, decreases the free volume and 
generally restricts the mobility of the matrix chains, thereby increasing $T_{\mathrm{g}}$. Fig. 6 shows TMA expansion curves for neat PPS and nanocomposites with different SWCNT loading, and the $T_{\mathrm{g}}$ values derived from the plots are summarized in Table 4. A strong dependence of this transition temperature on the CNT type and content is found. Composites reinforced directly with SWCNTs only show small rises in $T_{\mathrm{g}}$ compared to that of neat PPS $\left(89^{\circ} \mathrm{C}\right)$, of about 1,7 and $6^{\circ} \mathrm{C}$ for $0.1,0.5$ and $1.0 \mathrm{wt} \%$ loadings, respectively. This is related with the poor nanotube dispersion found for these nanocomposites [23], in particular for that with the highest concentration where discrete nanotube-rich domains rather than a CNT network were observed, hence the PPS chains would flow independently of the nanotubes, and their motion should be comparable to those of the neat polymer. In contrast, $T_{\mathrm{g}}$ of nanocomposites incorporating grafted fillers increases gradually with the SWCNT content, and the maximum increment (almost $20^{\circ} \mathrm{C}$ ) corresponds to the composite with $1.0 \mathrm{wt} \%$ effective loading. This outstanding increase should be ascribed to the very strong binding of the polymer molecules to the SWCNT surface attained through the covalent anchoring, combined with the enhanced matrix-filler compatibility due to the presence of the aminated derivative that results in improved dispersion, hence large PPS-SWCNT interfacial contact area. Another reason is the formation of hydrogen bonds between the amine groups of $\mathrm{PPS}-\mathrm{NH}_{2}$ and the $\mathrm{COOH}$ groups present onto the surface of the acid-treated SWCNTs. All these facts provoke an effective immobilization of the polymer chains, leading to a strong $T_{\mathrm{g}}$ enhancement, remarkably larger than that reported by the addition of the same amount of MWCNTs [13,15] or SWCNTs wrapped in PEI as a compatibilizer [18].

\subsubsection{Coefficient of thermal expansion}

The coefficient of linear thermal expansion (CTE) is an important thermomechanical property used in the design of polymer composites for engineering applications. A low CTE is desirable to maintain the dimensional stability of the material, and can be obtained by dispersing hard nanofillers with low CTE within the matrix. CNTs are known to have low CTE [42], hence it is expected that their addition reduces considerably this property. Table 4 presents the CTE data at 25 and $120^{\circ} \mathrm{C}$ obtained from the slopes of TMA curves (Fig. 6). In the glassy state, the CTE of neat PPS is about $58 \times 10^{-6} /{ }^{\circ} \mathrm{C}$, and decreases gradually upon addition of increasing SWCNT loadings, by up to $28 \%$ for PPS/PPS- $\mathrm{NH}_{2}-\mathrm{g}-\mathrm{SWCNT}$ (1.0 wt\%). Such noticeable drop should arise from the increase in the matrix stiffness due to the presence of the SWCNTs that hinder the expansion of the PPS chains, restricting its thermally induced movements, combined with their very homogenous dispersion within the matrix that provides a high level of polymer constraint.
Regarding PPS/SWCNT nanocomposites, the CTE reductions are smaller, around half of those attained with the grafted fillers. An analogous behaviour of CTE diminution below $T_{\mathrm{g}}$ has been reported for PVDF/SWCNT [37] and polyimide (PI)/CNT [43] nanocomposites. As expected, the CTE values at $120^{\circ} \mathrm{C}$ are considerably higher than those measured at room temperature, albeit the data display an opposite trend. Above $T_{\mathrm{g}}$, the CTE increases slightly with the SWCNT content, being about $8 \%$ for the composite with the highest loading of grafted fillers, while for the reference composites the increments are very small. The reason for the higher CTEs could be the increase in the excluded volume of the embedded CNTs at high temperature due to the contribution from both the phonon modes and Brownian motions [44] that should be higher in the case of the grafted SWCNTs albeit would be limited by confinement effects. These results suggest that CTEs can be tuned by tailoring the CNT functionalization process, which may find applications for smart materials and thermal management.

\subsubsection{Heat deflection temperature}

The temperature at which a polymeric sample deforms under a particular load is the heat deflection temperature (HDT), and is an important parameter when a material is being used for hightemperature structural applications. The incorporation of hard nanofillers such as clays [45] or CNTs [46] into thermoplastic matrices has been reported to enhance the HDT by increasing $T_{\mathrm{g}}$, raising the crystallinity and/or reinforcing. Table 4 summarizes the HDT data for neat PPS $\left(110^{\circ} \mathrm{C}\right)$ and different nanocomposites. The addition of the SWCNTs (except for $0.1 \mathrm{wt} \%$ non-grafted fillers) leads to a rise in this parameter, being particularly more pronounced for nanocomposites with covalent bonds, by up to $16{ }^{\circ} \mathrm{C}$ at $1.0 \mathrm{wt} \%$ loading. This significant improvement probably arises from the simultaneous increase in the three aforementioned factors influencing the HDT, whilst the small reduction found upon direct addition of very low SWCNT contents should be related to the decrease in crystallinity observed for that composite (Table 1) combined with a negligible change in $T_{\mathrm{g}}$ (Table 4) and a small reinforcement effect. To evaluate the reinforcing efficiency of both types of fillers, the Young's modulus $E$ and tensile strength $\sigma_{y}$ of the nanocomposites were measured as a function of temperature, and the results are presented in Fig. 7a and b, respectively, and listed in Table 5 . In the whole temperature range studied the PPS- $\mathrm{NH}_{2}-\mathrm{g}$-SWCNTs lead to significant improvements in both the matrix rigidity and strength, with increments in $E$ and $\sigma_{y}$ at $25^{\circ} \mathrm{C}$ and $1.0 \mathrm{wt} \%$ loading of $55 \%$ and $58 \%$, respectively. The reinforcement effect of the same amount of non-grafted fillers is considerably less pronounced, about $21 \%$ and $27 \%$, respectively, and the direct incorporation of $0.1 \mathrm{wt} \%$

Table 5

Young's modulus $E$ and tensile strength $\sigma_{y}$ at different temperatures for PPS and the different nanocomposites.

\begin{tabular}{|c|c|c|c|c|c|c|c|}
\hline Material (SWCNT content) & $E_{0}(\mathrm{GPa})$ & $E_{25}(\mathrm{GPa})$ & $E_{55}(\mathrm{GPa})$ & $E_{90}(\mathrm{GPa})$ & $E_{120}(\mathrm{GPa})$ & $E_{150}(\mathrm{GPa})$ & $E_{200}(\mathrm{GPa})$ \\
\hline PPS & $2.11 \pm 0.07$ & $2.01 \pm 0.09$ & $1.93 \pm 0.06$ & $1.20 \pm 0.07$ & $0.43 \pm 0.02$ & $0.25 \pm 0.01$ & $0.10 \pm 0.01$ \\
\hline PPS/SWCNT (0.1 wt $\%)$ & $2.21 \pm 0.09$ & $2.19 \pm 0.06$ & $2.04 \pm 0.08$ & $1.27 \pm 0.05$ & $0.45 \pm 0.02$ & $0.25 \pm 0.02$ & $0.18 \pm 0.01$ \\
\hline PPS/SWCNT (0.5 wt\%) & $2.39 \pm 0.08$ & $2.29 \pm 0.10$ & $2.13 \pm 0.09$ & $1.65 \pm 0.08$ & $0.51 \pm 0.03$ & $0.37 \pm 0.01$ & $0.24 \pm 0.01$ \\
\hline PPS/SWCNT (1.0 wt\%) & $2.50 \pm 0.11$ & $2.44 \pm 0.13$ & $2.32 \pm 0.09$ & $1.91 \pm 0.09$ & $0.60 \pm 0.02$ & $0.46 \pm 0.03$ & $0.28 \pm 0.02$ \\
\hline PPS/PPS-NH ${ }_{2}-g-S W C N T(0.1 w t \%)$ & $2.45 \pm 0.10$ & $2.37 \pm 0.11$ & $2.23 \pm 0.08$ & $1.49 \pm 0.07$ & $0.54 \pm 0.03$ & $0.33 \pm 0.02$ & $0.23 \pm 0.01$ \\
\hline PPS/PPS-NH ${ }_{2}-g-S W C N T(0.5 w t \%)$ & $2.90 \pm 0.11$ & $2.78 \pm 0.12$ & $2.67 \pm 0.08$ & $1.94 \pm 0.06$ & $0.68 \pm 0.04$ & $0.43 \pm 0.02$ & $0.33 \pm 0.02$ \\
\hline \multirow[t]{2}{*}{ PPS/PPS-NH $\mathrm{N}_{2}$-g-SWCNT (1.0 wt\%) } & $3.26 \pm 0.14$ & $3.10 \pm 0.13$ & $2.92 \pm 0.11$ & $2.15 \pm 0.09$ & $0.79 \pm 0.04$ & $0.58 \pm 0.03$ & $0.40 \pm 0.02$ \\
\hline & $\sigma_{y, 0}(\mathrm{MPa})$ & $\sigma_{y, 25}(\mathrm{MPa})$ & $\sigma_{y, 55}(\mathrm{MPa})$ & $\sigma_{y, 90}(\mathrm{MPa})$ & $\sigma_{y, 120}(\mathrm{MPa})$ & $\sigma_{y, 150}(\mathrm{MPa})$ & $\sigma_{y, 200}(\mathrm{MPa})$ \\
\hline PPS & $61.5 \pm 2.7$ & $59.7 \pm 2.2$ & $57.5 \pm 1.3$ & $47.9 \pm 1.8$ & $31.8 \pm 0.9$ & $24.6 \pm 0.6$ & $16.6 \pm 0.8$ \\
\hline PPS/SWCNT (0.1 wt\%) & $70.8 \pm 2.9$ & $66.9 \pm 2.4$ & $63.2 \pm 1.6$ & $49.0 \pm 1.4$ & $34.0 \pm 0.9$ & $24.5 \pm 0.8$ & $18.0 \pm 0.5$ \\
\hline PPS/SWCNT (0.5 wt\%) & $76.4 \pm 2.5$ & $73.5 \pm 2.7$ & $68.5 \pm 1.8$ & $55.9 \pm 1.3$ & $41.3 \pm 1.4$ & $30.6 \pm 1.1$ & $22.7 \pm 0.7$ \\
\hline PPS/SWCNT (1.0 wt\%) & $80.0 \pm 3.2$ & $76.3 \pm 2.8$ & $72.4 \pm 1.7$ & $61.3 \pm 1.9$ & $47.6 \pm 1.2$ & $38.3 \pm 0.9$ & $27.7 \pm 0.7$ \\
\hline PPS/PPS-NH ${ }_{2}-g-S W C N T(0.1 w t \%)$ & $75.1 \pm 2.3$ & $72.5 \pm 2.9$ & $68.0 \pm 1.7$ & $56.6 \pm 2.0$ & $43.3 \pm 1.8$ & $32.6 \pm 1.4$ & $26.0 \pm 1.0$ \\
\hline PPS/PPS-NH ${ }_{2}-g-S W C N T(0.5$ wt $\%)$ & $87.4 \pm 3.0$ & $84.7 \pm 2.8$ & $81.2 \pm 2.2$ & $66.2 \pm 1.3$ & $49.9 \pm 1.1$ & $39.0 \pm 1.6$ & $29.4 \pm 0.9$ \\
\hline PPS/PPS-NH ${ }_{2}-\mathrm{g}-\mathrm{SWCNT}(1.0 \mathrm{wt} \%)$ & $95.6 \pm 3.1$ & $93.5 \pm 3.3$ & $87.4 \pm 2.5$ & $67.5 \pm 2.6$ & $54.3 \pm 2.1$ & $43.2 \pm 1.5$ & $29.9 \pm 1.1$ \\
\hline
\end{tabular}


acid-treated SWCNTs only raises $E$ and $\sigma_{y}$ by $8 \%$ and $12 \%$. Further, all the nanocomposites show a strong reduction in stiffness and strength at $T>T_{\mathrm{g}}$, since the ductile flow of the matrix chains is accentuated in this temperature region. In the rubbery state (i.e. $150{ }^{\circ} \mathrm{C}$ ) the increments in the modulus and strength of PPS at $1.0 \mathrm{wt} \%$ loading are $115 \%$ and $80 \%$ for the grafted fillers, as well as $32 \%$ and $38 \%$ for the non-grafted, respectively. Interestingly, the reinforcement effect is found to be more pronounced at high temperatures, which can be explained considering that the temperature softens the matrix while the SWCNT modulus is not very sensitive to temperature [47]. In summary, it is confirmed that the integration of the SWCNTs via covalent functionalization provides effective reinforcement to the PPS matrix, increasing its $T_{g}$ and degree of crystallinity, thus resulting in a significant rise in the HDT. In contrast, their direct incorporation reduces the matrix crystallinity, slightly raises its $T_{g}$ and leads to small/moderate reinforcement effects depending on the concentration. When a minor SWCNT content is added, the reduction in crystallinity probably overweighs the small increase in stiffness, thereby decreasing slightly the HDT, whereas at higher loadings the reinforcement effect prevails, hence the HDT rises to some extent (see Table 5).

\section{Conclusions}

The effect of PPS- $\mathrm{NH}_{2}$-g-SWCNTs on the thermal and thermomechanical behaviour of PPS was studied, and the results were compared to those of reference composites reinforced directly with the SWCNTs. DSC experiments revealed an increase in the crystallization temperature and degree of crystallinity of the matrix upon addition of the grafted nanofillers, whilst a fall in both parameters was found for composites filled with non-grafted SWCNTs. Larger increments in the degradation temperatures of the matrix under both inert and oxidative atmospheres were attained, as well as improved flame retardant performance, showing reduced peak heat release rate and higher ignition temperature. For both types of nanocomposites, a progressive rise in thermal conductivity was found with the SWCNT loading. In the glassy state, the conductivity of all the samples increased almost linearly with temperature, while in the rubbery state it decreased slightly for the reference composites albeit remained merely unchanged for those with grafted fillers. The rule of mixtures and the model by Nan et al. described satisfactorily the room temperature thermal conductivity of PPS/SWCNT at low nanofiller contents, although showed noticeable deviations at $1.0 \mathrm{wt} \%$. However, the experimental data for PPS/ PPS- $\mathrm{NH}_{2}$-g-SWCNT were systematically above the predictions. The integration of the SWCNTs via covalent grafting provided effective reinforcement to the PPS matrix, particularly at high temperatures, raising strongly the HDT and $T_{\mathrm{g}}$. In contrast, the direct incorporation of the fillers led to smaller increments in stiffness and strength, increasing marginally these two parameters. At temperatures below $T_{\mathrm{g}}$, the CTEs of both types of nanocomposites diminished compared to that of neat PPS, especially for those with grafted fillers. However, the CTEs above $T_{\mathrm{g}}$ increased to some extent due to the contribution from phonon modes and Brownian motions. The outstanding improvements found in the thermal and thermomechanical properties of PPS are ascribed to the strong matrix-filler interactions attained through the covalent anchoring, combined with their enhanced compatibility due to the presence of the aminated derivative that results in very homogenous SWCNT dispersion, hence large interfacial contact area between the composite phases. The covalent functionalization route applied in this work is a promising approach to improve the thermomechanical performance of thermoplastic polymers for use in high-temperature applications.

\section{Acknowledgments}

Financial support from the Ministerio de Ciencia e Innovación (MICINN, Project MAT2010-21070-C02-01) is gratefully acknowledged. MN would like to acknowledge the Ministerio de Economía y Competitividad (MINECO) for a 'Ramon y Cajal' senior research fellowship. AD would like to thank to the Consejo Superior de Investigaciones Científicas (CSIC) for a JAE postdoctoral contract.

\section{References}

[1] Wayne H, Hill HW, Brady DG. Encyclopaedia of polymer science and engineering, vol. 11. New York: Willey; 1988. p. 531.

[2] Geibel JF, Campbell RW. Polymers, polyarylene sulphide. In: McKetta J, Cunningham WA, editors. Encyclopedia of chemical processing and design, vol. 40. New York: Marcel Dekker; 1992. p. 94.

[3] Lopez LC, Wilkes GL]. Poly(p phenylene sulfide) an overview of an important engineering thermoplastic. Macromol Sci, Rev Macromol Chem Phys 1989:C29:83-151.

[4] Naffakh M, Marco C, Gómez MA, Gómez-Herrero J, Jiménez l. Use of inorganic fullerene-like $\mathrm{WS}_{2}$ to produce new high-performance polyphenylene sulfide nanocomposites: role of the nanoparticle concentration. J Phys Chem B 2009;113:10104-11.

[5] Naffakh M, Marco C, Gómez MA, Gómez-Herrero J, Jiménez I. Unique isothermal crystallization behavior of novel polyphenylene sulfide/inorganic

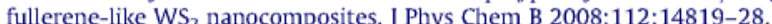

[6] Christian J, Schwartz A, Bahadur S. Studies on the tribological behavior and transfer film-counterface bond strength for polyphenylene sulfide filled with nanoscale alumina particles. Wear 2000;237:261-73.

[7] Bahadur S, Sunkara C. Effect of transfer film structure, composition and bonding on the tribological behavior of polyphenylene sulfide filled with nano particles of $\mathrm{TiO}_{2}, \mathrm{ZnO}$, CuO and SiC. Wear 2005;258:1411-21.

[8] Thostenson ET, Ren Z, Chou T-W. Advances in the science and technology of carbon nanotubes and their composites: a review. Compos Sci Technol 2001;61:1899-912.

[9] Spitalsky Z, Tasis D, Papagelis K, Galiotis C. Carbon nanotube-polymer composites: chemistry, processing, mechanical and electrical properties. Prog Polym Sci 2010;35:357-401.

[10] Coleman JN, Khan U, Blau W], Gun'ko YK. Small but strong: a review of the mechanical properties of carbon nanotube-polymer composites. Carbon 2006;44:1624-52.

[11] Diez-Pascual AM, Guan J, Simard B, Gomez-Fatou MA. Poly(phenylene sulphide) and poly(ether ether ketone) composites reinforced with singlewalled carbon nanotube buckypaper: I- structure, thermal stability and crystallization behaviour. Composites: Part A 2012;43:997-1006.

[12] Diez-Pascual AM, Guan J, Simard B, Gomez-Fatou MA. Poly(phenylene sulphide) and poly(ether ether ketone) composites reinforced with singlewalled carbon nanotube buckypaper: $\mathrm{Il}$ - mechanical properties, electrical and thermal conductivity. Composites: Part A 2012;43:1007-15.

[13] Yang J, Xu T, Lu A, Zhang Q Tan H, Fu Q. Preparation and properties of poly ( $p$ phenylene sulfide)/multiwall carbon nanotube composites obtained by melt compounding. Compos Sci Technol 2009;69:147-53.

[14] Jiang Z, Hornsby P, McCool R, Murphy A. Mechanical and thermal properties of polyphenylene sulfide/multiwalled carbon nanotube composites. J Appl Polym Sci 2012;123:2676-83.

[15] Wu D, Wu L, Zhou W, Yang T, Zhang M. Study on physical properties of multiwalled carbon nanotube/poly(phenylene sulfide) composites. Polym Eng Sci 2009;49:1727-35.

[16] Yu S, Wong WM, Hu X, Juay YK. The characteristics of carbon nanotubereinforced poly (phenylene sulfide) nanocomposites. J Appl Polym Sci 2009:113:3477-83.

[17] Naffakh M, Diez-Pascual AM, Marco C, Ellis G. Morphology and therma properties of novel poly(phenylene sulfide) hybrid nanocomposites based on single-walled carbon nanotubes and inorganic fullerene-like $\mathrm{WS}_{2}$ nanoparticles. J Mater Chem 2012;22:1418-25.

[18] Díez-Pascual AM, Naffakh M, Marco C, Ellis G. Mechanical and electrical properties of carbon nanotube/poly(phenylene sulphide) composites incorporating polyetherimide and inorganic fullerene-like nanoparticles. Composites: Part A 2012;43:603-12.

[19] Díez-Pascual AM, Naffakh M, Marco C, Ellis G. Rheological and tribological properties of carbon nanotube/thermoplastic nanocomposites incorporating inorganic fullerene-like WS nanoparticles. J Phys Chem B 2012;116:7959-69.

[20] Morishita T, Matsushita M, Katagiri Y, Fukumori K. Noncovalent functionalization of carbon nanotubes with maleimide polymers applicable to high melting polymer-based composites. Carbon 2010;48:2308-16.

[21] Diez-Pascual AM, Naffakh M. Grafting of an aminated poly(phenylene sulfide) derivative to functionalized single-walled carbon nanotubes. Carbon 2012;50:857-68.

[22] Diez-Pascual AM, Naffakh M. Synthesis and characterization of nitrated and aminated poly(phenylene sulfide) derivatives. Mater Chem Phys 2012;131:605-14. 
[23] Diez-Pascual AM, Naffakh M. Towards the development of poly(phenylene sulphide) based nanocomposites with enhanced mechanical, electrical and tribological properties. Mater Chem Phys 2012;135:348-57.

[24] Brady DG. Poly(phenylene sulfide) - how, when, why, where, and where now.] Appl Polym Sci Appl Polym Symp 1981;36:231-9.

[25] Díez-Pascual AM, Naffakh M, Gómez MA, Marco C, Ellis G, GónzalezDomínguez JM, et al. Development and characterization of PEEK/carbon nanotube composites. Carbon 2009;47:3079-90.

[26] Jeon I-Y, Lee H-J, Choi YS, Tan L-S, Baek J-B. Semimetallic transport in nanocomposites derived from grafting of linear and hyperbranched poly(phenylene sulfide)s onto the surface of functionalized multi-walled carbon nanotubes. Macromolecules 2008;41:7423-32.

[27] Shenogin S, Bodapati A, Xue L, Ozisik R, Keblinski P. Effect of chemical functionalization on thermal transport of carbon nanotube composites. Appl Phys Lett 2004;85:2229-31.

[28] Wang M, Pramoda KP, Goh SH. Enhancement of the mechanical properties of poly(styrene-co-acrylonitrile) with poly(methyl methacrylate)-grafted multiwalled carbon nanotubes. Polymer 2005;46:11510-6.

[29] Diez-Pascual AM, Martinez G, Martinez MT, Gomez MA Novel nanocomposites reinforced with hydroxylated poly(ether ether ketone)grafted carbon nanotubes. J Mater Chem 2010;20:8247-56.

[30] van Krevelen DW. Flammability and flame retardancy of organic high polymers. In: Advances in Chemistry: Thermally Stable Polymers. Warsawa; 1977. p. 119.

[31] Kashiwagi T, Gruke E, Hilding J, Groth K, Harris R, Butler K, et al. Thermal and flammability properties of polypropylene/carbon nanotube nanocomposites. Polymer 2004;45:4227-39.

[32] Schartel B, Potschke P, Knoll U, Goad MA. Fire behavior of polyamide 6/ multiwall carbon nanotube nanocomposites. Eur Polym J 2005;41:1061-70.

[33] Hull TR, Stec AA. Polymers and fire. In: Hull TR, Kandola BK, editors. Fire retardancy of polymers: new strategies and mechanisms. UK: Royal Society of Chemistry; 2009 [chapter 1].

[34] Agarwall R, Saxena NS, Sharma KB, Thomas S, Sreekala MS. Temperature dependence of effective thermal conductivity and thermal diffusivity of treated and untreated polymer composites. J Appl Polym Sci 2003;89:1708-17.

[35] Peters JE, Papavassiliou DV, Grady BP. Unique thermal conductivity behaviour of single-walled carbon nanotube-polystyrene composites. Macromolecules 2008;41:7274-7.

[36] Han Z, Fina A. Thermal conductivity of carbon nanotubes and their polymer nanocomposites: a review. Prog Polym Sci 2011;36(7):914-44.

[37] Xu Y, Ray G, Abdel-Magid B. Thermal behaviour of single-walled carbon nanotube polymer-matrix composites. Composites: Part A 2006;37:114-21.

[38] Yan HX, Xiao Y, Li ZM. Effects of intertube coupling and tube chirality on thermal transport of carbon nanotubes. J Appl Phys 2006;99:124305-9.

[39] Zhao X, Ye L. Preparation, structure and property of polyoxymethylene/carbon nanotubes thermal conductive composites. Polym Sci Part B: Polym Phys 2010;48:905-12

[40] Nan CW, Shi Z, Lin Y. A simple model for thermal conductivity of carbon nanotube-based composites. Chem Phys Lett 2003;375:666-9.

[41] Meng FY, Ogata S, Xu DS, Shibutani Y, Shi SQ. Thermal conductivity of an ultrathin carbon nanotube with an X-shaped junction. Phys Rev B 2007;75:205403.

[42] Bandow S. Radial thermal expansion of purified multiwall carbon nanotubes measured by X-ray diffraction. J Appl Phys Parts 2 1997;36:1403-5.

[43] Bae S-H, Park Y-H, Kim J-H. Preparation and characterization of polyimide/ carbon-nanotube composites. Macromol Res 2007;15:357-62.

[44] Wei C, Srivastava D, Cho K. Thermal expansion and diffusion coefficients of carbon nanotube-polymer composites. Nano Lett 2002;2:647-50.

[45] Kojima Y, Usuki A, Kawasumi M, Okada A, Fukushima Y, Kirauchi T. Mechanical properties of nylon 6-clay hybrid. J Mater Res 1993;8:1185-9.

[46] Pascual J, Peris F, Boronat T, Fenollar O, Balart R. Study of the effects of multiwalled carbon nanotubes on mechanical performance and thermal stability of polypropylene. Polym Eng Sci 2011;52:733-40.

[47] Lu JP. Elastic properties of carbon nanotubes and nanoropes. Phys Rev Lett 1997; $79: 1297-300$ 